\title{
Referencial curricular gaúcho para o Ensino Médio de 2021: contexto de produção, ciências da natureza e questões étnico-raciais
}

\author{
Gaúcho curricular reference for High School 2021: context of \\ production, natural sciences and ethnic-racial issues
}

Referente curricular gaúcho para la Ensenanza Secundaria 2021: contexto de producción, ciencias de la naturaleza y cuestiones étnicoraciales

Neusa Teresinha Massoni ${ }^{1}$; Alan Alves-Brito ${ }^{2}$; Alexander Montero Cunha ${ }^{3}$

\section{RESUMO}

A rápida construção do Referencial Curricular Gaúcho para o Ensino Médio tornou saliente muitos dos contrassensos presentes nas políticas educacionais no Brasil. Neste trabalho discutimos alguns destes contrassensos a partir de um olhar com tripla dimensão: sobre a participação da academia no contexto de produção, sobre a área de Ciências da Natureza no Ensino Médio e sobre as questões étnico-raciais presentes (ou não) nesta mesma área. Nossa análise mostra uma limitada participação da academia decorrente da forma enrijecida de construção do Referencial Curricular Gaúcho, desenvolvido a partir da Base Nacional Comum Curricular (BNCC). Esta forma enrijecida resultou em um tratamento superficial dos conhecimentos a serem trabalhados nas Ciências da Natureza justificado inadequadamente por uma abordagem interdisciplinar. Resultou também em um afastamento das políticas educacionais em voga até 2015 , um reducionismo do direito à educação e uma total falta de discussões étnico-raciais na área de ciências. São resultados que trazem preocupação ao não considerar as complexas relações existentes entre os agentes participativos do sistema educacional brasileiro e gaúcho, o que poderá trazer prejuízos futuros à Educação Científica.

Palavras-chave: Referencial Curricular Gaúcho; Área de Ciências da Natureza; Políticas Públicas; Relações Étnico-Raciais.

\begin{abstract}
The rapid development of a "Gaúcho" Curriculum Reference for High School, highlights many of the contradictions existing in educational policies in Brazil. In this work, we discuss some of these contradictions concentrating on: the context of production and the participation of the academy; the Natural Sciences in High School; and the ethnic-racial issues present (or not). Our analysis highlights the rigid form of the Curriculum Reference, which has been developed from the National Common Curricular Base (BNCC), a document that has been plagued with problems. A decline in the participation of the academy to merely technical issues while disregarding the knowledge produced in the area for decades has resulted in a superficial treatment of the knowledge worked in the area of Natural Sciences, with a drastic reduction in the workload which has been inadequately justified by an interdisciplinary approach. It also resulted in a complete departure from the

${ }^{1}$ Licenciada Física, Mestre em Física e Doutora em Ciências. É Professora Associada na Universidade Federal do Rio Grande do Sul (UFRGS) e docente permanente do Programa de Pós-Graduação em Ensino de Física do Instituto de Física da UFRGS, Porto Alegre/RS - Brasil. E-mail: neusa.massoni@ufrgs.br

${ }^{2}$ Bacharel em Física, Mestre e Doutor em Ciências. É Professor Adjunto no Instituto de Física da Universidade Federal do Rio Grande do Sul e docente permanente do Programa de Pós-Graduação em Ensino de Física do Instituto de Física da UFRGS, Porto Alegre/RS - Brasil. E-mail: alan.brito@ufrgs.br

${ }^{3}$ Licenciado em Física, Mestre e Doutor em Educação. É Professor Adjunto no Instituto de Física da Universidade Federal do Rio Grande do Sul (UFRGS), Porto Alegre/RS - Brasil. E-mail: amcunha@ufrgs.br
\end{abstract}


educational policies until around 2015, a reduction in the education and learning right and a total lack of ethnicracial discussions in the science area. These results highlight our enormous concerns, for not considering the complex relationships that exist between the participatory agents of the Brazilian and Rio Grande do Sul educational system, as well as the imminent withdrawal of students from the Natural Sciences field.

Keywords: "Gaúcho" Curriculum Reference; Area of Natural Sciences; Public Policies; Ethnic-Racial Relations.

\section{RESUMEN}

El rápido desarrollo de un Referente Curricular "Gaúcho" para la enseñanza secundaria, resalta muchas de las contradicciones existentes en las políticas educativas en Brasil. En este trabajo discutimos algunas de estas contradicciones concentrándonos en: el contexto de producción y la participación de la academia; las Ciencias de la Naturaleza en la enseñanza secundaria; y las cuestiones étnico-raciales presentes (o no). Nuestro análisis destaca la forma rígida del Referente Curricular, que ha sido desarrollado a partir de la Base Curricular Común Nacional (BNCC), un documento que ha estado plagado de problemas. El declive de la participación de la academia a cuestiones meramente técnicas, sin tener en cuenta los conocimientos producidos en el área durante décadas, se ha traducido en un tratamiento superficial del conocimiento trabajado en el área de las Ciencias de la Naturaleza, con una drástica reducción de la carga de trabajo que ha sido inadecuadamente justificado por un enfoque interdisciplinario. También resultó en una desviación total de las políticas educativas hasta alrededor de 2015, una reducción en el derecho a la educación y el aprendizaje y una falta total de discusiones étnico-raciales en el área de las ciencias. Estos resultados resaltan nuestra enorme preocupación, por no considerar las complejas relaciones que existen entre los agentes participativos del sistema educativo brasileño y de Rio Grande do Sul, así como el inminente retiro de estudiantes del campo de las Ciencias de la Naturaleza.

Palabras clave: Referente Curricular Gaúcho; Área de Ciencias Naturales; Políticas públicas; relaciones étnicoraciales.

\section{INTRODUÇÃO}

A partir de um olhar que contemple o horizonte das políticas públicas norteadoras da Educação Básica desde a Constituição Federal de 1988 (BRASIL, 1988), poderemos perceber que houve, em que pesem algumas oscilações e nuances nas últimas décadas, um alinhamento na interpretação de que devemos compreender o papel da Educação como um direito humano. A partir da Constituição Federal de 1988, que se consolidou na Lei de Diretrizes e Bases - LDB (BRASIL, 1996), a educação é um dos direitos sociais, e o Estado tem o dever de oferecer escolarização básica pública e gratuita a todas as crianças e adolescentes de 4 a 17 anos, sendo que a Emenda Constitucional no 59 tornou obrigatória também a oferta pública e gratuita a todos os brasileiros que não puderam realizá-la na idade recomendada. Direito à Educação, portanto, envolve um conjunto de ações para o acesso, a permanência e a aprendizagem de todos, com a observância de princípios como liberdade de expressão, de ensinar e de aprender, pluralismo de ideais e de concepções pedagógicas, bem como a efetivação de políticas de ações afirmativas, inclusão e relações étnico-raciais (Leis n. 10.639/2003 e 11.645/2008), de acessibilidade de pessoas com deficiências (Leis n. 10.098/2000 e 13.146/2015 em consonância com a Convenção sobre os Direitos das Pessoas com Deficiência de 2006), garantia de oferta obrigatória de disciplina de Língua Brasileira de Sinais (LIBRAS) nos cursos de formação de professores (Decreto n. 5.626/2005), entre outras. Tal entendimento da Educação encontra suporte também na legislação infraconstitucional como: o Estatuto da Criança e do Adolescente (Lei 8.069/1990, decorrente da Convenção sobre os Direitos da Criança de 1989, assinada pelo Brasil); a Educação em Direitos Humanos prevista no Plano Nacional de Educação em Direitos Humanos de 
2007 e terceiro Programa Nacional de Direitos Humanos de 2010, que tomaram como estratégia a formação em nível superior em direitos humanos, e o Parecer CNE/CP n. 8/2012 e a Resolução CNE/CP n. 1/2012, que afirmam a necessidade de especificação dos sujeitos de direitos, privados historicamente, de os usufruírem de forma plena, e resultante de conquistas de movimentos sociais e de compromissos assumidos pelo país em acordos internacionais. É de citar também o direito a um ambiente ecologicamente equilibrado, previsto na Constituição, e estabelecido por legislações como a Lei 9.795/1999 e as Diretrizes da Educação Ambiental (Resolução CNE/CP n. 1/2012) em busca da conscientização crítica sobre a produção e o consumo predatórios e a construção de uma cultura de enfrentamento das mudanças climáticas e seus impactos sobre a biodiversidade e a segurança alimentar das populações humanas.

Notaremos, nesse olhar, que houve a partir da segunda metade da década de 2010 uma ruptura no modo como devemos interpretar o Direito à Educação, passando a vê-la exclusivamente como um direito à aprendizagem. Essa virada pode ser pontuada na Medida Provisória 746/2016, que tornou obrigatório o Novo Ensino Médio por itinerários, e que resultou em uma sequência de normativos (entre 2016 e 2020) cuja consequência foi a modificação de vários aspectos relacionados à Educação: a gestão democrática do ensino público foi substituída por uma noção de governança associando-a a indicadores técnicos; e a qualificação docente deixa de ser uma função do Estado e passa a ser um investimento pessoal com o advento da Resolução CNE/CP n. 2/2019 (BRASIL, 2019), com consequências duras como a mercantilização da Educação e a precarização do trabalho docente; as estruturas do sistema educacional antes entendidas como espaços de acesso e inclusão passam a ser vistas como espaço voltado à formação técnica e sua aprendizagem fica restrita a temas e objetos de aprendizagem previstos na Base Nacional Comum Curricular da Educação Básica (BNCC; BRASIL 2017; 2018); o engajamento ć́vico e profissional de caráter emancipatório e transformador da sociedade fica, assim, redefinido para um sentido de engajamento meramente profissional.

Os documentos oficiais homologados a partir do ponto de inflexão antes mencionado (Medida Provisória 746/2016) são: (i) Lei n. 13.415/2017 que institui a Política de Fomento à Implementação de Escolas de Ensino Médio em Tempo Integral; (ii) Resolução CNE/CP n. 2/2017, que institui e orienta a implantação da Base Nacional Comum Curricular, a ser respeitada obrigatoriamente ao longo das etapas e respectivas modalidades no âmbito da Educação Básica; (iii) Resolução CNE/CP n. 4/2018, que institui a Base Nacional Comum Curricular na Etapa do Ensino Médio (BNCC-EM), como etapa final da Educação Básica; (iv) Resolução CNE/CEB n. 3/2018, que atualiza as Diretrizes Curriculares Nacionais para o Ensino Médio; (v) Resolução CNE/CP n. 2/2019, que define as Diretrizes Curriculares Nacionais para a Formação Inicial de Professores para a Educação Básica e institui a Base Nacional Comum para a Formação Inicial de Professores da Educação Básica (BNC-Formação), complementada pela Portaria n. 882 de 23 de outubro de 2020 que homologa o Parecer CNE/CP n. 14/2020, que implementa Diretrizes Curriculares Nacionais para a Formação Continuada de Professores da Educação Básica e Base Nacional Comum para a Formação Continuada de Professores da Educação Básica (BNC-Formação Continuada).

Alinhado a esses normativos, o Estado do Rio Grande do Sul produziu um documento intitulado Referencial Curricular Gaúcho do Ensino Médio, que em 2021 foi enviado para as Instituições de Ensino Superior (IES) atuantes no Estado visando colher contribuições: vejamos como isso se deu e se houve espaço para um efetivo diálogo construtivo com a academia. 


\section{CONTEXTO DE PRODUÇÃO DA BNCC E DO REFERENCIAL CURRICULAR GAÚCHO E A PARTICIPAÇÃO DA ACADEMIA}

O Plano Nacional de Educação (PNE) de 2014 (BRASIL, 2014) pode ser considerado como o início da BNCC enquanto agenda nas políticas educacionais no Brasil. Antes do PNE, possíveis referências à BNCC poderiam ser encontradas em três dos artigos originais da Lei de Diretrizes e Bases da Educação Brasileira (LDB) de 1996:

Art. 26. Os currículos do ensino fundamental e médio devem ter uma base nacional comum, a ser complementada, em cada sistema de ensino e estabelecimento escolar, por uma parte diversificada, exigida pelas características regionais e locais da sociedade, da cultura, da economia e da clientela (transcrição do artigo original e que foi modificado em 2013).

Art. 38. Os sistemas de ensino manterão cursos e exames supletivos, que compreenderão a base nacional comum do currículo, habilitando ao prosseguimento de estudos em caráter regular.

Art. 64. A formação de profissionais de educação para administração, planejamento, inspeção, supervisão e orientação educacional para a educação básica, será feita em cursos de graduação em pedagogia ou em nível de pós-graduação, a critério da instituição de ensino, garantida, nesta formação, a base comum nacional. (BRASIL, 1996: s.n.) (grifo nosso)

Todos estes artigos referem-se a uma base nacional comum em minúsculo, sem uma forma definida e na qual os próprios PCNs podem ser entendidos como sendo esta base (BRASIL, 2000). Todas as demais referências à Base Nacional Comum Curricular (agora em maiúsculas) presentes na LDB foram inseridas pela Medida Provisória no 746/2016 e substituídas posteriormente com novas adições pela Lei Federal no 13.415 de 2017, comumente relacionada ao "Novo Ensino Médio". Esta Lei é reconhecida por inserir os itinerários formativos nesse nível de ensino, ainda que esta Lei não se restrinja a legislar sobre o Ensino Médio. A Medida Provisória, como comentado na introdução deste texto, tem um grande peso porque marca um ponto de inflexão das políticas nacionais para a Educação em nosso país.

No PNE de 2014 é possível encontrar quatro referências à base nacional comum curricular, todas em minúsculas, e presentes como estratégias para determinadas metas:

2.2) pactuar entre União, Estados, Distrito Federal e Municípios, no âmbito da instância permanente de que trata $0 \S 5^{\circ}$ do art. 70 desta Lei, a implantação dos direitos e objetivos de aprendizagem e desenvolvimento que configuram a base nacional comum curricular do ensino fundamental;

3.3) pactuar entre União, Estados, Distrito Federal e Municípios, no âmbito da instância permanente de que trata o $\S 5^{\circ}$ do art. 70 desta Lei, a implantação dos direitos e objetivos de aprendizagem e desenvolvimento que configurarão a base nacional comum curricular do ensino médio;

7.1) estabelecer e implantar, mediante pactuação interfederativa, diretrizes pedagógicas para a educação básica e a base nacional comum dos currículos, com direitos e objetivos de aprendizagem e desenvolvimento dos (as) alunos (as) para cada ano do ensino fundamental e médio, respeitada a diversidade regional, estadual e local;

15.6) promover a reforma curricular dos cursos de licenciatura e estimular a renovação pedagógica, de forma a assegurar o foco no aprendizado do (a) aluno (a), dividindo a carga horária em formação geral, formação na área do saber e didática 
específica e incorporando as modernas tecnologias de informação e comunicação, em articulação com a base nacional comum dos currículos da educação básica, de que tratam as estratégias 2.1, 2.2, 3.2 e 3.3 deste PNE; (BRASIL, 2014).

Para além da palavra "currículo", não há muito o que diferenciar em relação à forma como a base aparece inicialmente na LDB da que está presente no PNE. É preciso investigar mais a fundo os processos envolvidos por trás desta inclusão. Por ora, o que se seguiu à LDB foram os Parâmetros Curriculares Nacionais (PCNs), um documento orientador da Educação Brasileira que, ao se referir a base nacional comum, defendia uma liberdade para a definição curricular pelos sistemas de ensino:

\begin{abstract}
É importante compreender que a Base Nacional Comum não pode constituir uma camisa-de-força que tolha a capacidade dos sistemas, dos estabelecimentos de ensino e do educando de usufruírem da flexibilidade que a lei não só permite, como estimula. Essa flexibilidade deve ser assegurada, tanto na organização dos conteúdos mencionados em lei, quanto na metodologia a ser desenvolvida no processo de ensino-aprendizagem e na avaliação. (BRASIL, 2000, p. 18).
\end{abstract}

A BNCC possui, em nossa interpretação, uma estrutura mais centralizadora no que se refere ao currículo e materializa uma virada em relação ao que era previsto nos PCNs do início da década de 2000, no sentido de assumir, em certa medida, essa "camisa-de-força". Para compreendermos a sua forma final (documento da BNCC), é importante nos remetermos ao seu processo de implantação enquanto agenda política. Tarlau e Moeller (2020) resgatam o processo de inclusão da base no PNE destacando a sua inspiração na Base Curricular (Common Core) norte-americana. As autoras destacam também o papel fundamental da Fundação Lemann no encaminhamento da BNCC brasileira enquanto agenda política. Num processo denominado de Consenso por Filantropia, a fundação fez "uso estratégico de recursos econômicos, da produção de conhecimento, do poder da mídia e das redes formais e informais, a entidade transformou a qualidade e a equidade da educação em problemas com soluções técnicas, assim obtendo amplo apoio para essa iniciativa política." (TARLAU; MOLLER, 2020, p. 593).

A participação democrática na produção da BNCC com ampla participação social e acadêmica é constantemente enfatizada e divulgada como forma de legitimar o seu processo de construção, como descrito no próprio site da BNCC do Ministério da Educação:

A Base foi elaborada em cumprimento às leis educacionais vigentes no País e contou com a participação de variadas entidades, representativas dos diferentes segmentos envolvidos com a Educação Básica nas esferas federal, estadual e municipal, das universidades, escolas, instituições do terceiro setor, professores e especialistas em educação brasileiros e estrangeiros. Sua primeira versão, disponibilizada para consulta pública entre os meses de outubro de 2015 e março de 2016, recebeu mais de 12 milhões de contribuições dos diversos setores interessados. Em maio de 2016, uma segunda versão, incorporando o debate anterior, foi publicada e novamente discutida com cerca de 9 mil professores em seminários organizados por Consed (Conselho Nacional de Secretários de Educação) e Undime (União Nacional dos Dirigentes Municipais de Educação), em todas as unidades da federação, entre 23 de junho e 10 de agosto de 2016. Os resultados desses seminários foram sistematizados pela UnB (Universidade de Brasília) e subsidiaram a produção de um relatório expressando o posicionamento conjunto de Consed e Undime. Esse relatório foi a principal referência para a elaboração da versão final, que também foi revista por especialistas e gestores do MEC com base nos diversos pareceres críticos recebidos e que foi colocada em consulta pública, a partir da qual recebeu-se mais de 44 mil contribuições. (MEC, s.d.).

A legitimidade deste processo "democrático" pode ser, entretanto, questionada, tanto na capacidade de conciliar as milhões de contribuições (FREITAS et al., 2018), quanto na efetiva escuta dos diversos 
atores em sua diversidade (TARLAU; MOELLER, 2020). Não nos cabe aqui resgatar todo esse processo de produção da BNCC, mas nos interessa voltarmos especificamente para a participação da academia.

Em suas três versões oficiais é possível encontrar uma "ampla" participação de professores e pesquisadores acadêmicos, a exemplo da terceira versão, na função de especialistas, de pesquisadores e de leitores críticos, entre outras (BRASIL, 2018). Nos cabe pensar, entretanto, sobre essa forma de participação da academia e, para isso, traremos duas dimensões complementares e possíveis de análise.

A primeira dimensão se refere a academia enquanto referência na produção de conhecimento científico sobre Educação e, mais especificamente, sobre Currículo. Há uma área própria de pesquisa denominada Currículo institucionalizada inclusive pela Coordenação de Aperfeiçoamento de Pessoal de Nível Superior (CAPES) (7.08.05.00-8 - Currículo) que congrega financiamento, discussões, conhecimento e pessoas. Há também uma associação específica, a Associação Brasileira de Currículo ( $A B d C)$ criada em 2011, que também estimula a produção de conhecimento na área e envolve pesquisadores reconhecidos internacionalmente. A produção de conhecimentos sobre políticas curriculares já possui uma história legitimada e que permite afirmações como a seguir:

... a coerência com os princípios democráticos da Constituição e da LDB aponta para a busca, cada vez maior, de flexibilização e não para o movimento de unificação curricular, que se tem mostrado -em diferentes países e também no Brasil - favorável à manutenção de hegemonias e a consequente exclusão social e escolar de tudo o que se distancia desses padrões. (ABdC, 2017; p.1).

Se o conhecimento científico produzido na área aponta que o caminho deve ser o contrário do que estamos tomando, nos resta perguntar como se chegou a este formato centralizador para a BNCC, ainda mais se já possuíamos um documento anterior mais flexível. $O$ já referido trabalho de Tarlau e Moeller (2020) nos mostra esse caminhar e como uma concepção de Educação relacionada ao empresariado foi determinante para tal processo. Nos resta constatar que no processo de construção da BNCC o conhecimento acadêmico produzido pela área não era convergente com o que se desejava no Consenso por Filantropia.

A segunda dimensão a que iremos nos referir está relacionada aos limites da ação dos acadêmicos impostos pela primeira dimensão. Se os conhecimentos científicos produzidos na área de Currículo não eram convergentes com a proposição desejada para a BNCC, qual poderia ser a sua participação? Primeiramente, podemos distinguir a participação dos acadêmicos nas duas primeiras versões da BNCC em relação à terceira. A exemplo, Muneratto et al. (2020) fazem uma análise específica para os professores da área de Ciências da Natureza mostrando o baixo capital científico dos redatores da área da terceira versão em relação aos redatores da segunda versão. Dois fatores podem ser representativos para a falta de diálogo com a academia: a total reformulação da estrutura da área de Ciências da Natureza na terceira versão da base, em que se deixa de ter as especificidades para as disciplinas de Física, Química e Biologia; e a rápida reorganização do Novo Ensino Médio (Medida Provisória no 746 de 2016 e Lei Federal no 13.415 de 2017) de um governo recém-empossado e proposto sem real participação social na tomada de decisões.

Podemos também nos referir, enquanto processos participativos, aos seminários regionais propostos para discutir a BNCC. Ao acompanhar um dos seminários estaduais, que agregou centenas de professores para avaliar a segunda versão da BNCC, Tarlau e Moeller (2020) perceberam um processo enrijecido e com poucas opções de interferência. A avaliação se fazia na concordância ou discordância 
de item por item presente na BNCC. O formato da avaliação e, o mais grave, o formato da BNCC, estavam dados, não havia espaço para a reformulação das estruturas em que se apresentavam. Os seminários representaram um processo técnico de adequação dos objetivos e direitos de aprendizagem ${ }^{4}$ apresentados e alguns professores se recusaram a participar deste processo (TARLAU; MOELLER, 2020).

Cabe aqui também perguntar sobre a participação dos redatores na produção das versões da BNCC. Considerando o Common Core norte-americano trazido como referência inicial ${ }^{5}$, o posicionamento das associações de pesquisa, como a Associação Brasileira de Currículo (ABdC), a organização dos seminários regionais nas primeiras versões da BNCC e a rápida implantação da terceira versão, não parece que a decisão sobre o formato da BNCC esteve em algum momento no âmbito de participação da academia e da pesquisa nela produzida.

Com este contexto sobre a participação da academia no processo de implantação da BNCC, podemos nos voltar para o momento que estamos agora vivenciando de definição dos currículos estaduais e municipais. Segundo a Lei do "Novo Ensino Médio":

Art. 12. Os sistemas de ensino deverão estabelecer cronograma de implementação das alterações na Lei no 9.394, de 20 de dezembro de 1996, conforme os arts. 20, 30 e 40 desta Lei, no primeiro ano letivo subsequente à data de publicação da Base Nacional Comum Curricular, e iniciar o processo de implementação, conforme o referido cronograma, a partir do segundo ano letivo subsequente à data de homologação da Base Nacional Comum Curricular. (BRASIL, 2017).

Cabe, assim, aos sistemas de ensino a implantação da BNCC. Especificidades colocadas à parte ${ }^{6}$, a organização da BNCC em habilidades já designa um certo formato rígido de currículo, ainda que o próprio documento da BNCC tente se afastar de sua associação direta a currículo:

BNCC e currículos têm papéis complementares para assegurar as aprendizagens essenciais definidas para cada etapa da Educação Básica, uma vez que tais aprendizagens só se materializam mediante o conjunto de decisões que caracterizam o currículo em ação. São essas decisões que vão adequar as proposições da BNCC à realidade local, considerando a autonomia dos sistemas ou das redes de ensino e das instituições escolares, como também o contexto e as características dos alunos. Essas decisões, que resultam de um processo de envolvimento e participação das famílias e da comunidade. (BRASIL, 2018, p. 16).

Podemos nos perguntar como é possível adequar as enrijecidas habilidades colocadas na BNCC à realidade local? É possível desconsiderar algumas das habilidades propostas na BNCC ao adequá-la à realidade local? É possível restringir o âmbito de ação destas habilidades? Será preciso demandar a participação da academia neste processo?

É possível termos alguns indicativos de resposta a essas perguntas ao analisarmos o Referencial Curricular Gaúcho que "está sendo construído". Os atores chamados para a adequação da BNCC à realidade local foram profissionais pertencentes à Rede Estadual de Educação, numa seleção cujo

\footnotetext{
${ }^{4} \mathrm{O}$ que foi chamado de objetivos e direitos de aprendizagem nas duas primeiras versões da BNCC foi denominado de competências e habilidades na terceira versão. (BRASIL, 2018).

${ }^{5}$ Em alguns momentos do processo de discussão da BNCC foram trazidas experiências internacionais outras, como a australiana e a chilena, que possuem grande similaridade com a norte-americana.
}

${ }^{6}$ A BNCC designa especificamente as habilidades que devem ser trabalhados ano a ano e por disciplina no Ensino Fundamental. Já as habilidades das áreas de Ciências da Natureza e Ciências Humanas no Ensino Médio não aparecem separadas ano a ano e nem por disciplinas. (BRASIL, 2018). 
edital foi lançado em 21 de setembro de 2020, o resultado foi publicizado em 30 de outubro de 2020 e a abertura à consulta pública ocorreu a partir de 30 de novembro de $2020^{7}$. Ou seja, segundo datas oficiais, os redatores tiveram um mês para essa adequação.

Exemplificamos como se tratou de um rápido processo, em que vemos como um dos resultados a seguinte adequação:

\section{(EM13CNT107)}

Habilidade BNCC: (EM13CNT107) Realizar previsões qualitativas e quantitativas sobre o funcionamento de geradores, motores elétricos e seus componentes, bobinas, transformadores, pilhas, baterias e dispositivos eletrônicos, com base na análise dos processos de transformação e condução de energia envolvidos - com ou sem o uso de dispositivos e aplicativos digitais -, para propor ações que visem a sustentabilidade.

\section{Habilidades RS:}

- Reconhecer grandezas físicas bem como suas unidades e conversões, envolvidas com o funcionamento de aparelhos eletroeletrônicos doméstico, bem como identificar os que consomem mais energia (Anos: $3^{\circ}$ ).

- Realizar previsões ou construir dispositivos eletroquímicos com base em conceitos físicos e químicos para interpretar resultados sobre potencial eletroquímico, percebendo os fenômenos deste tipo relacionados com 0 cotidiano. (Anos: $2^{\circ}$ e $3^{\circ}$ ) (SEDUC-RS, s.d.).

Uma adequação em que a habilidade da BNCC remete a um tipo de equipamento elétrico com função bem direcionada (que envolve a transformação de energia elétrica em outras e vice-versa) e em que as habilidades específicas do Rio Grande do Sul foram direcionadas para situações cotidianas não especificamente regionais. Tendo este caso como exemplo, o trabalho dos redatores parece ter sido prioritariamente o de desmembrar ou direcionar as habilidades previstas na BNCC, sem maiores possibilidades de readequação ${ }^{8}$.

A Secretaria de Educação do Rio Grande do Sul enviou em dezembro de 2020 o Referencial Curricular Gaúcho para apreciação do Conselho Estadual de Educação, que solicitou no início de março de 2021 às Instituições de Ensino Superior (IES) uma leitura avaliativa com possíveis contribuições, com prazo para a devolutiva para 31/03/2021. Em todo esse contexto e com prazo tão exíguo, a que resta à academia? Uma análise técnica do conteúdo do documento já que seu formato já está determinado? E se a academia não participar deste processo? Será ela tida intransigente não aceitando o diálogo com as demais instâncias do sistema educacional? Há/houve espaço ainda para diálogo nesse aligeirado processo?

\footnotetext{
${ }^{7}$ Datas extraídas do site oficial do Referencial Gaúcho: http://curriculo.educacao.rs.gov.br/

${ }^{8}$ Há textos introdutórios a cada seção do Referencial Gaúcho que também podem ter sido escritos pelos redatores, porém são as habilidades no formato que se encontram que são associados ao currículo a ser trabalhado.
} 


\section{CONTEXTO DE DISTRIBUIÇÕES AO REFERENCIAL CURRICULAR GAÚCHO: ÁREA DE CIÊNCIAS DA NATUREZA E AS SUAS TECNOLOGIAS}

\subsection{Formação Básica}

A partir de um exame do Referencial Curricular Gaúcho feito na Universidade Federal do Rio Grande do Sul nesse curto espaço de tempo, como dito, com um olhar focado na formação básica da Área de Ciências da Natureza, compreendemos que: i) a legislação nacional (LDB 9394/1996; Lei n.13.415/2017) prevê para o Ensino Médio uma carga horária para a formação geral básica de 1800h, complementada por Itinerários Formativos com 1200h, cobrindo uma carga horária total de 3000h; ii) a BNCC (BRASIL, 2017; 2018) busca garantir uma aprendizagem básica de conteúdos de Ciências da Natureza que se estende por toda a Educação Básica, iniciando nos Anos Iniciais do Ensino Fundamental; iii) reconhece-se que há a necessidade de normatizar, a partir das DCNEM (BRASIL, 2018), as aprendizagens básicas a serem construídas por todos os alunos da Rede Estadual; iv) é importante que haja espaços na formação escolar para o desenvolvimento dos projetos integradores, complementados pelo projeto de vida dos jovens, sendo que estão previstos: Itinerário Formativo Profissões I (Caminhos Rurais - Diversidades do Campo); Itinerário Formativo Profissões II (Caminhos no Contexto Organizacional - Diversidades na Gestão e Negócios); Itinerário Formativo Profissões III (Caminhos na Diversidade da Comunicação e Mídias Digitais); Itinerário Formativo Saúde I; Itinerário Formativo Saúde II; Itinerário Formativo Saúde III; Itinerário Formativo Sustentabilidade I; Itinerário Formativo Sustentabilidade II; Itinerário Formativo Sustentabilidade III; v) é relevante também promover ações formativas por meio da flexibilização curricular, com um olhar voltado para as profissões, às questões de saúde e de sustentabilidade, que são temas relevantes e alguns associados a questões sociocientíficas dos nossos tempos.

Diante desse cenário, foram feitas algumas colocações e enviadas ao Conselho Estadual de Educação com o objetivo de contribuir à reflexão, buscando compreender a lógica de construção do documento e, jamais, colocando a crítica pela crítica.

Pontuamos que o documento era longo (frente ao exíguo espaço de tempo destinado ao exame), contém partes repetidas, e alguns pontos específicos remetem o leitor a outros textos (citações) o que torna a leitura integral mais complexa (seria necessário ir em busca desses textos). Além disso, alguns conceitos no documento invocam a inovação e as novas tecnologias (e.g. nanotecnologia, DNA recombinante, biotecnologia, potencialidades de resíduos sólidos industriais etc.), mas que carregam em sua base muitos outros conceitos que são difíceis de aprofundar em um curto espaço de tempo escolar. Daí a importância crucial de uma carga horária mínima, como adiante se mencionará.

Nessa linha, causa preocupação a redução brusca no novo Ensino Médio da carga horária de disciplinas consideradas fundamentais para a formação de um pensamento fundamentado em princípios e conceitos científicos que estão na base dos campos da Física, da Química e da Biologia; princípios estes que sustentam as sofisticadas tecnologias disponíveis na sociedade moderna. Segundo a Portaria n. 289/2019 (publicada no Diário Oficial de 17/11/2019), os componentes curriculares Física e Biologia, passam de dois (2) períodos semanais nos três anos do Ensino Médio, para um (1) período semanal apenas no $1^{\circ}$ e $2^{\circ}$ anos no Novo Ensino Médio, e o componente curricular Química, passa de dois (2) períodos semanais nos três anos do Ensino Médio para um (1) 
período semanal nos três anos do Ensino Médio. Assim, todos os componentes curriculares da área de Ciências da Natureza sofrem redução de carga horária no novo Ensino Médio.

Permitimo-nos lançar um olhar mais focado ao componente curricular Física, dado que: 1) as modernas tecnologias - computadores, smartphones, tablets etc., indispensáveis para a interação social neste momento de pandemia, por exemplo - são baseadas em princípios físicos compreendidos no âmbito da Física Moderna e Contemporânea; 2) pesquisas recentes na área do Ensino de Física defendem que é possível mostrar aplicações práticas dos conteúdos de Física Quântica (AYENE et al., 2018; STEVENS; DELGADO; KRAJCIK, 2009), e fazer experimentos e discutir aspectos quânticos com uso de, por exemplo, lasers (CLAVIJO; WALTEROS; CORTÉS, 2019; MARKIN; MARKINA; EILKS, 2017) ou explorar atividades baseadas em leitura de textos científicos ou de divulgação científica (HÉRAUD; LAUTESSE; FERLIN; CHABOT, 2017); 3) que o Parecer CNE/CP n० 2/2015 que fundamentou a Resolução CNE/CP no 2, de $1^{\circ}$ de julho de 2015, que define as Diretrizes Curriculares Nacionais para a formação inicial em nível superior (cursos de licenciatura, cursos de formação pedagógica para graduados e cursos de segunda licenciatura) e para a formação continuada ofereceu um panorama preocupante, enfatizando que a estimativa de concluintes de Licenciaturas em Física em 2013 em relação aos ingressantes de 2010 era baixa (em torno de 20,5\%) e que do universo de 50.543 docentes de Física, apenas $26,8 \%$ possuíam formação específica), e que pesquisas mais recentes mostram um quadro ainda mais preocupante, por exemplo, NASCIMENTO (2020, p. 3) ao analisar microdados obtidos do Censo Escolar de 2018 argumenta que em média, apenas 20\% dos professores de Física das escolas públicas estaduais do país possuem formação específica); 4) trazendo esse panorama para os dias atuais, pode ser mostrado que egressos do Ensino Médio percebem a baixa empregabilidade e o pouco prestígio da carreira docente em Física, e pouco se interessam pela Licenciatura o que pode reduzir ainda mais a procura por formação em nível superior, podendo gerar um apagão na área.

Por essas razões, apontamos como muito importante que seja preservada uma carga horária na formação básica geral na área de Ciências da Natureza, como forma de permitir um adequado aprofundamento e compreensão, por parte dos estudantes, de princípios e conceitos científicos fundamentais previstos para serem trabalhados nos nove (9) itinerários do Referencial Curricular Gaúcho.

Não restam dúvidas de que é fundamental oferecer oportunidades de vivências interdisciplinares a ocorrer no interior dos nove (9) Itinerários desenhados para a Área de Ciências da Natureza; certamente contribuirão para uma formação cidadã crítica. Contudo, defendemos que uma formação disciplinar é necessária, até mesmo para garantir que os "projetos integradores" previstos nos Itinerários da área possam se desenvolver com o suporte disciplinar sólido e que o estudante adquira profundidade de conhecimentos para se encaminhar com mais segurança para o mercado de trabalho, ou para o Ensino Superior, conforme seu projeto de vida.

Percebemos com grande preocupação, como já mencionado, que o número de períodos semanais, pela Portaria n. 289/2019 (publicada no Diário Oficial de 17/11/2019), tenha caído no Novo Ensino Médio das escolas da Rede Estadual do Rio Grande do Sul, dificultando, em nossa interpretação, que se cumpra o normativo das DCNEM de 2018 (Parecer CNE/CP n. 15/2017 e Resolução CNE/CP n. 2/2017) que altera a LDB (BRASIL, 1996) e que coloca como finalidade do Ensino Médio a "consolidação e o aprofundamento dos conhecimentos adquiridos no Ensino Fundamental, possibilitando o prosseguimento dos estudos". 
É elogiável que a nova organização do Ensino Fundamental promova uma interface de continuidade, como menciona o documento do Referencial Gaúcho, com uma abordagem de contato com o mundo físico e natural desde o Ensino Infantil, retomado e ampliado no Ensino Fundamental (nas três unidades temáticas, Matéria e Energia, Vida e Evolução, Terra e Universo). Contudo, um exame dos temas e objetos de conhecimento da BNCC, permite ver que os conhecimentos da área de Ciências da Natureza compartilhados nessa etapa da Educação Básica são bastante gerais e sem aprofundamento, embora, sem dúvida importantes.

É elogiável também que o Referencial Gaúcho tenha se preocupado com o "protagonismo do estudante, no seu projeto de vida e no respeito à diversidade e aos interesses das juventudes" e objetivam uma formação humana e valorativa.

No entanto, reafirmamos que para permitir uma adequada compreensão do mundo físico, bem como para refletir aspectos da natureza e evolução histórica da ciência, é indispensável que se garanta espaço e carga horária a um aprofundamento da estrutura formal das ciências que compõem a área de Ciências da Natureza.

Educadores da área de Ensino de Ciências refletem há décadas que o objetivo da aprendizagem de sala de aula na etapa final da Educação Básica, quando os jovens têm maior maturidade e adquirem uma estrutura cognitiva mais formal, é alcançado se as experiências de aprendizagem anteriores facilitarem a aprendizagem de tarefas nas aulas subsequentes. E que, tanto melhor será se os estudantes conseguem utilizar os conhecimentos teóricos na prática, desenvolvendo habilidades para aplicar estes conhecimentos em situações-problemas desafiadoras, em estudos investigativos, em projetos, como também na resolução de problemas.

No ensino de Física, em particular, os objetivos subjacentes à escolha do conteúdo da matéria são relevantes para: (1) planejar estudos em que os principais desenvolvimentos em Física, até essa altura, se apresentam num todo lógico e integrado; (2) apresentar a física como uma conquista intelectual que é parte da atividade e do desempenho humanos (FINLAY, 1960).

Para Finlay, o problema principal na implementação destes objetivos é construir currículos que possam ser ensinados por professores da educação básica a estudantes desse nível que, simultaneamente, reflitam claramente os princípios básicos ou subjacentes de várias áreas da Física de forma a dar-se um papel central às ideias e atitudes predominantes com elas relacionadas. $\mathrm{A}$ fundamentação lógica se assenta na escolha particular de tópicos que proporcionem uma base estável e amplamente transferível para a assimilação e integração de novos conhecimentos; e ofereçam uma base tão vasta e forte quanto possível para aprendizagens posteriores de aspectos da ciência, com significado e grande aplicabilidade.

Como já dito, é elogiável que ideias gerais e mais abrangentes de Física, Química e Biologia sejam compartilhadas e discutidas desde o Ensino Fundamental, sendo, ano a ano, retomadas e revisitadas. Tal estrutura pode ser pensada como um "currículo em espiral" (BRUNER, 1960). Pontuamos, contudo, que o lugar de ensinar matérias que representam as grandes áreas da Física - aquelas que mais contribuem para os pontos de vista da Física Contemporânea sobre o mundo físico é o Ensino Médio. Daí a importância de se garantir uma carga horária mínima.

A força dessas grandes ideias reside na sua vasta aplicabilidade e na unidade que provoca uma compreensão daquilo que, superficialmente, podem parecer fenômenos não relacionados. Em termos pedagógicos esta escolha tem virtudes. Pode-se pensar na criação de critérios através dos quais se 
podem selecionar e organizar matérias com vistas à coerência que os próprios estudantes pretendem obter, e para alcançar uma aprendizagem significativa com possibilidade de retenção (AUSUBEL, 2003).

Adicionalmente, um exame de alguns livros do Programa Nacional do Livro Didático - PNLD 2021, que já estão disponíveis na internet - permite ver com preocupação que as bases da Física, Química e Biologia estão superficialmente contempladas ali, o que pode aprofundar as desigualdades entre estudantes de escolas públicas e aqueles de escolas privadas, pois estas preocupam-se, igualmente, em atender às competências e habilidades previstas na BNCC (BRASIL, 2018) e em manter a formação disciplinar aprofundada na área de Ciências da Natureza. Se desejamos reduzir as desigualdades sociais através da Educação, enquanto direito social, não podemos permitir que a instituição escolar (através dos conteúdos, métodos pedagógicos, avaliações etc.) perpetue a dominação social (BOURDIEU, PASSERON, 1975 apud NOGUEIRA; NOGUEIRA, 2017, p. 96).

\subsection{Aplicabilidade do Art. 26A da LDB}

Como discutido e aprofundado em Alves-Brito et al. (2018), passados 18 anos de aprovação da Lei $10.639 / 2003$ que instituiu o artigo 26A da LDB, bem como suas outras formas de regulamentação (Resolução CNE/CP 01/2004 e Parecer CNE/CP 03/2004) - redação modificada pela Lei 11.645/2008 - o ensino da História e da Cultura Afro-Brasileira e Indígena, segue sendo um dos grandes desafios da educação contemporânea, sobretudo no contexto da Educação em Ciências da Natureza:

Art. 26-A. Nos estabelecimentos de ensino fundamental e de ensino médio, públicos e privados, torna-se obrigatório o estudo da história e cultura afro-brasileira e indígena. (Redação dada pela Lei no 11.645, de 2008).

\$ $\mathbf{1 0}^{\circ} \mathrm{O}$ conteúdo programático a que se refere este artigo incluirá diversos aspectos da história e da cultura que caracterizam a formação da população brasileira, a partir desses dois grupos étnicos, tais como o estudo da história da África e dos africanos, a luta dos negros e dos povos indígenas no Brasil, a cultura negra e indígena brasileira e o negro e o índio na formação da sociedade nacional, resgatando as suas contribuições nas áreas social, econômica e política, pertinentes à história do Brasil. (Redação dada pela Lei nº 11.645, de 2008).

§ $\mathbf{2}^{\mathbf{0}}$ Os conteúdos referentes à história e cultura afro-brasileira e dos povos indígenas brasileiros serão ministrados no âmbito de todo o currículo escolar, em especial nas áreas de educação artística e de literatura e história brasileiras. (Redação dada pela Lei no 11.645, de 2008).

De maneira global, nossa primeira observação fundamental é a de que sim precisamos repensar os referenciais curriculares das Ciências da Natureza para incluir, de forma completa, as prerrogativas do artigo 26A nessa importante área de conhecimento, sobretudo no que significa o Brasil póspandemia e como as Ciências da Natureza nos ajudam a articular "sujeito, objeto e natureza" no século XXI.

Nesse sentido, vale também salientar que as Diretrizes Curriculares Nacionais de 2015 já preconizam alterações curriculares na formação de professores para levar em conta as questões étnico-raciais, de gênero e suas intersecções com outros marcadores sociais da diferença. Os cursos de Licenciatura em Física da UFRGS foram alterados para se adequarem às DCNs 2015, conforme descrevemos em detalhes em artigo recente (MASSONI; BRUCKMANN; ALVES-BRITO 2020). 
Particularmente, no que diz respeito à Área de Ciências da Natureza há no Referencial Curricular Gaúcho completa ausência de discussões e proposições focadas no combate explícito ao racismo, no reconhecimento e na valorização à diversidade étnico-racial brasileira e no fomento ao respeito e à valorização das diferenças como parte integrante do currículo. Alguns temas, associados ao que se objetiva em cada módulo, até aparecem ao longo do texto, mas sem grandes aprofundamentos, com presença tímida nos conteúdos programáticos apresentados e, mais grave, com pouco destaque/olhar para o Rio Grande do Sul. Entendemos que o documento como um todo constitui-se num apanhado de pontos fundamentais de documentos mais gerais, sem se preocupar com as necessidades e contextos particulares do Rio Grande do Sul. Ainda que tenhamos consciência que o documento é apenas um Referencial, não podemos esquecer que, na prática, ele acaba definindo o modo de operar no "chão da escola". Por exemplo, é preciso ampliar o conhecimento sobre as culturas africanas, afrobrasileiras e indígenas para podermos desconstruir e eliminar estereótipos e desenvolvermos atitudes positivas quanto à pluralidade. Já que a Astronomia ocupa um papel fundamental na BNCC, argumentamos que Astronomia nas Culturas tem muito a contribuir, do Ensino Fundamental ao Ensino Médio, para fortalecer as Leis 10.639/2003 e 11.645/2008 na educação básica, sobretudo no que concerne a visibilização e aprofundamentos práticos e epistêmicos da contribuição africana e indígena ao Estado do RS. No momento, entretanto, tanto na BNCC quanto no Referencial Curricular Gaúcho, Astronomia ocupa papel de destaque focada apenas nas contribuições europeias.

A abordagem da Educação para as Relações Étnico-Raciais (artigo 26A da LDB) é, por natureza, interdisciplinar. Não há como falar de "racismo" sem intercruzamentos de gênero, classe e sem contextualização histórica, epistêmica, estética, o que exige propostas interdisciplinares, o que não vemos tampouco latente na atual proposta de Ciências da Natureza presente no Referencial Curricular Gaúcho.

Entre os pontos observados no documento que impõem barreiras ao cumprimento efetivo dos objetivos do artigo 26A da LDB, elencamos: (i) visão enviesada da ciência para os marcos civilizatórios da Grécia/Europa e extrema percepção positivista, embora algumas frases sugiram outra coisa; (ii) os conteúdos da formação específica são demasiadamente focados na parte técnica, como comentado na Introdução. Formação tecnicista é privilegiada. Essa observação é fundamental, pois a percepção epistemológica e a visão da ciência são cruciais quando se deseja trabalhar, no "chão da escola", as questões étnico-raciais na construção das ciências; (iii) não vemos, explicitamente, análises críticas sobre como a ciência (e as Ciências da Natureza em particular) contribui para o aprofundamento de desigualdades étnico-raciais; (iv) racismo científico, como pseudociência, não aparece. As questões sociais da ciência que estão "implicitamente" dadas no documento estão focadas em questões mais técnicas ou generalistas do conhecimento (universalidade versus localidade); (v) não identificamos, em Ciências da Natureza, relações fortes do corpo/saúde/identidade/qualidade de vida que dessem base ao artigo 26A da LDB; (vi) saberes/olhares científicos e tecnológicos dos povos tradicionais gaúchos foram desconsiderados.

Destacamos mais abaixo algumas observações específicas de cada disciplina.

\section{A) Modalidade Formação Geral Básica:}

\section{Formação Geral - Parte comum do currículo alinhada à BNCC e DCN do EM}

- As Leis 10.639/2003 e 11.645/2008 não são mencionadas. Isso é grave porque, quase sempre, essas leis só são citadas em conteúdos de História, das Artes ou de Atividades Físicas no 
Ensino Médio. Há um desequilíbrio, pois a Política Nacional de Resíduos Sólidos (PNRS) - Lei 12.305/2010, por exemplo, é citada.

\section{- Embora o documento começa enfatizando que}

...as DCNEM assinalam que o Ensino Médio é um direito de todas as juventudes e tem como princípios a formação integral do estudante a partir do seu projeto de vida, a pesquisa como prática pedagógica, o respeito aos direitos humanos e à diversidade, a sustentabilidade ambiental e a indissociabilidade entre teoria e prática no processo de ensino e de aprendizagem, permeando a Educação formal com a prática social, por meio da flexibilidade curricular, proporcionando ao aluno o contato efetivo com sua comunidade, por meio da cultura, do lazer, do contato com o meio ambiente e com o mercado de trabalho.

e reconheça que as ciências são construções humanas, ocorrendo em diferentes contextos sociais, históricos e culturais, falta, em todo o documento, orientações referentes às questões étnico-raciais na formação geral básica do EM e sua articulação em o EF.

- A única vez que a palavra etnia aparece é como segue:

\section{(EM13CNT208)}

Habilidade BNCC: (EM13CNT208) Aplicar os princípios da evolução biológica para analisar a história humana, considerando sua origem, diversificação, dispersão pelo planeta e diferentes formas de interação com a natureza, valorizando e respeitando a diversidade étnica e cultural humana.

Habilidades RS:

- Conhecer a história da evolução humana no planeta, sua diversidade e relação com o meio. (Anos: $1^{0}, 2^{\circ}$ e $3^{\circ}$ ).

- Compreender que a população humana no planeta é composta por uma variedade de etnias e que cada uma delas tem sua cultura própria respeitando assim a diversidade em sua ampla constituição. (Anos: $1^{\circ}, 2^{\circ}$ e $3^{\circ}$ ).

- As palavras raça/racismo não aparecem no texto.

- As palavras "direitos humanos" e "diversidade" aparecem, respectivamente, 1 e 12 vezes. Ainda assim, muitas vezes em contexto universalista dos termos, sem contextualização à luz do que preconiza o artigo 26A.

- Os marcos históricos de construção da ciência estão fortemente alicerçados na Grécia. Além disso, a proposta curricular tem forte viés europeu, sem qualquer reflexão crítica sobre a contribuição de outros povos e formas de organização de conhecimentos e saberes.

- Há demasiada valorização de aspectos técnicos de Física, Química e Biologia, numa visão positivista da ciência e, paradoxalmente, contrária à ideia de "ciências naturais" como construções humanas, limitadas no tempo e no espaço.

- Não há qualquer articulação de aspectos históricos, filosóficos, sociais e antropológicos das ciências naturais no EM. Não há como fazer valer o artigo 26A sem levar em conta percepções não hegemônicas do que é a ciência (ROSA; ALVES-BRITO; KARINE, 2020). 
- Embora mencionados explicitamente no âmbito da Física, de forma geral sentimos falta, no currículo, do formalismo e de caminhos de articulação relacionados à Ciência, Tecnologia, Sociedade e Ambiente, aspecto crucial para fazer valer o artigo 26A. Deveria-se, nesse caso, citar explicitamente questões sociocientíficas vinculadas às questões do artigo 26A.

- Nenhuma das três (3) grandes Competências/Habilidades do documento mencionam diretamente questões fundamentais ligadas ao artigo 26A. A Competência 3 menciona, timidamente, a necessidade de divulgar "suas descobertas e conclusões a públicos variados".

- Nota-se que as vulnerabilidades são discutidas em Biologia, mas, outra vez, numa visão tecnicista e biologizante, como se reproduz aqui.

\section{(EM13CNT207)}

Habilidade BNCC: (EM13CNT207) Identificar, analisar e discutir vulnerabilidades vinculadas às vivências e aos desafios contemporâneos aos quais as juventudes estão expostas, considerando os aspectos físico, psicoemocional e social, a fim de desenvolver e divulgar ações de prevenção e de promoção da saúde e do bem-estar.

Habilidades RS: Propor ações coletivas com o intuito informar e instruir o estudante, identificando e incorporando valores importantes para si e para o coletivo quanto: DST's, Vícios, Drogas, Diversidade e sexualidade, vinculados aos estudos de: Bioquímica, Sistema nervoso, Compostos orgânicos. (Anos: $1^{\circ}, 2^{\circ}$ e $3^{\circ}$ ).

- Na sequência, apresenta-se timidamente a possibilidade de discussão do que propõe o artigo 26A. No entanto, dependendo dos professores/gestores em atuação, a discussão do artigo ficará comprometida. É muito fácil, na perspectiva da Biologia, chegar-se à discussão de que somos todos "raça humana". Discussão também limitada à Biologia.

\section{(EM13CNT208)}

Habilidade BNCC: (EM13CNT208) Aplicar os princípios da evolução biológica para analisar a história humana, considerando sua origem, diversificação, dispersão pelo planeta e diferentes formas de interação com a natureza, valorizando e respeitando a diversidade étnica e cultural humana.

Habilidades RS:

- Conhecer a história da evolução humana no planeta, sua diversidade e relação com o meio. (Anos: $1^{0}, 2^{\circ}$ e $3^{\circ}$ ).

- Compreender que a população humana no planeta é composta por uma variedade de etnias e que cada uma delas tem sua cultura própria respeitando assim a diversidade em sua ampla constituição. (Anos: $1^{\circ}, 2^{\circ}$ e $3^{\circ}$ ).

- Cabe o mesmo comentário anterior, pois as proposições relacionadas ao artigo 26A estão muito nas "entrelinhas".

\section{(EM13CNT305)}

Habilidade BNCC: (EM13CNT305) Investigar e discutir o uso indevido de conhecimentos das Ciências da Natureza na justificativa de processos de discriminação, segregação e privação de direitos individuais e coletivos, em diferentes contextos sociais e históricos, para promover a equidade e o respeito à diversidade. 
Habilidades RS: Desenvolver uma postura crítica e ética em relação a utilização de conhecimentos científicos na vida em sociedade. (Anos: $1^{\circ}, 2^{\circ}$ e $3^{\circ}$ ).

\section{B) Itinerário Formativo de Aprofundamento Ensino Médio}

- A palavra raça/racismo não aparece no texto.

- A palavra étnico aparece uma (1) vez no texto.

- A palavra diversidade aparece algumas dezenas de vezes, nem sempre no contexto do artigo 26A, mas mesmo quando aparentemente ligada, está nas "entrelinhas".

- Percebemos que em todos os itinerários formativos, as habilidades e os objetivos são sempre os mesmos. Dois objetivos estariam, em princípio, mais relacionados ao artigo 26A. Mas, de novo, da forma que são colocados, os objetivos são amplos e vagos. Dificilmente darão condições aos professores de fazer a escolha para as questões de interesse.

\section{Itinerário Formativo Profissões I}

\section{"Caminhos Rurais - Diversidades do Campo"}

Habilidade 6

Discutir a importância da preservação e da conservação da biodiversidade, considerando parâmetros qualitativos e quantitativos; e avaliar os efeitos da ação humana e das políticas ambientais para a garantia da sustentabilidade do planeta.

Habilidade 7

Identificar, analisar e discutir vulnerabilidades vinculadas às vivências e aos desafios contemporâneos aos quais a juventude está exposta, considerando os aspectos físicos, psicoemocionais e sociais, a fim de desenvolver e divulgar ações de prevenção e de promoção da saúde e do bem-estar.

\section{Itinerário Formativo Profissões II}

\section{"Caminhos no Contexto Organizacional - Diversidades na Gestão e Negócios"}

Habilidade 8

Discutir a importância da preservação e conservação da biodiversidade, considerando parâmetros qualitativos e quantitativos, e avaliar os efeitos da ação humana e das políticas ambientais para a garantia da sustentabilidade do planeta.

Habilidade 9

Identificar, analisar e discutir vulnerabilidades vinculadas às vivências e aos desafios contemporâneos aos quais as juventudes estão expostas, considerando os aspectos físico, psicoemocional e social, a fim de desenvolver e divulgar ações de prevenção e de promoção da saúde e do bem-estar. 


\section{Itinerário Formativo Profissões III}

\section{"Caminhos na Diversidade da Comunicação e Mídias Digitais"}

Habilidade 6

Discutir a importância da preservação e conservação da biodiversidade, considerando parâmetros qualitativos e quantitativos, e avaliar os efeitos da ação humana e das políticas ambientais para a garantia da sustentabilidade do planeta.

Habilidade 7

Identificar, analisar e discutir vulnerabilidades vinculadas às vivências e aos desafios contemporâneos aos quais as juventudes estão expostas, considerando os aspectos físico, psicoemocional e social, a fim de desenvolver e divulgar ações de prevenção e de promoção da saúde e do bem-estar.

- O texto se apresenta demasiadamente técnico.

\section{Itinerário Formativo Saúde I}

Habilidade 6

Justificar a importância da preservação e conservação da biodiversidade, considerando parâmetros qualitativos e quantitativos, e avaliar os efeitos da ação humana e das políticas ambientais para a garantia da sustentabilidade do planeta.

Habilidade 7

Identificar e analisar vulnerabilidades vinculadas aos desafios contemporâneos aos quais as juventudes estão expostas, considerando as dimensões física, psicoemocional e social, a fim de desenvolver e divulgar ações de prevenção e de promoção da saúde e do bem-estar.

\section{Itinerário Formativo Saúde II}

Habilidade 6

Justificar a importância da preservação e conservação da biodiversidade, considerando parâmetros qualitativos e quantitativos, e avaliar os efeitos da ação humana e das políticas ambientais para a garantia da sustentabilidade do planeta.

Habilidade 7

Identificar e analisar vulnerabilidades vinculadas aos desafios contemporâneos aos quais as juventudes estão expostas, considerando as dimensões física, psicoemocional e social, a fim de desenvolver e divulgar ações de prevenção e de promoção da saúde e do bem-estar.

\section{Itinerário Formativo Saúde III}

Habilidade 6

Discutir a importância da preservação e conservação da biodiversidade, considerando parâmetros qualitativos e quantitativos, e avaliar os efeitos da ação humana e das políticas ambientais para a garantia da sustentabilidade do planeta. 
Habilidade 7

Identificar, analisar e discutir vulnerabilidades vinculadas às vivências e aos desafios contemporâneos aos quais as juventudes estão expostas, considerando os aspectos físico, psicoemocional e social, a fim de desenvolver e divulgar ações de prevenção e de promoção da saúde e do bem-estar.

\section{Itinerário Formativo Sustentabilidade I}

Habilidade 6

Identificar, analisar e discutir vulnerabilidades vinculadas às vivências e aos desafios contemporâneos aos quais as juventudes estão expostas, considerando os aspectos físico, psicoemocional e social, a fim de desenvolver e divulgar ações de prevenção e de promoção da saúde e do bem-estar.

Habilidade 7

Construir questões, elaborar hipóteses, previsões e estimativas, empregar instrumentos de medição e representar e interpretar modelos explicativos, dados e/ou resultados experimentais para construir, avaliar e justificar conclusões no enfrentamento de situações-problema sob uma perspectiva científica.

Idem para os: Itinerário Formativo Sustentabilidade II e Itinerário Formativo Sustentabilidade III

\section{Eletiva: As Cores e os Aromas da vida}

- Na disciplina eletiva "As cores e os aromas da vida", onde estão os quesitos raça/cor nessa discussão?

- Na disciplina Eletiva: A Estética e a Beleza e os padrões sociais - $2^{\circ}$ ano, onde estão as estéticas do racismo à brasileira que, como sabemos, é de marca?

- Na disciplina eletiva "Eletiva: O futuro do planeta Terra em nossas mãos", percebe-se que esses objetivos se repetem e, ao nosso ver, também são vagos à luz do artigo 26A.

\section{Eletiva: $O$ futuro do planeta Terra em nossas mãos - 10, $2^{\circ}$ e $3^{\circ}$ Ano}

- Discutir a importância da preservação e conservação da biodiversidade, considerando parâmetros qualitativos e quantitativos, e avaliar os efeitos da ação humana e das políticas ambientais para a garantia da sustentabilidade do planeta.

- Identificar, analisar e discutir vulnerabilidades vinculadas às vivências e aos desafios contemporâneos aos quais as juventudes estão expostas, considerando os aspectos físico, psicoemocional e social, a fim de desenvolver e divulgar ações de prevenção e de promoção da saúde e do bem-estar.

Por fim, concluímos esta subseção salientando que as observações acima são totalmente enviesadas e pessoais, e que partilhamos nossas contribuições aos documentos muito mais em um viés construtivo, como já comentado. 


\section{CONSIDERAÇÕES FINAIS}

Objetivamos neste texto mostrar e compartilhar nossa preocupação ao analisar o Referencial Curricular Gaúcho para o Ensino Médio, focando o olhar na formação básica da Área de Ciências da Natureza e na Educação para as Relações Étnico-Raciais, documento esse que surge no bojo da guinada que as políticas públicas sofreram em nosso país nos últimos cinco (5) anos, e que pode ser interpretada como um retrocesso em relação às conquistas alcançadas nas décadas anteriores, a partir da Constituição de 1988. Há nos tempos atuais um retrocesso em esferas mais amplas, que agrava as assimetrias sociais (REIS, 2021), pois, segundo o autor, atinge a democracia, os direitos humanos, a justiça social e o bem-estar de indivíduos, sociedades e ambientes. Com respeito à Educação, o retrocesso observado nas políticas públicas em nosso país tem reflexos tanto na Educação Básica como na formação de professores; nem todas as escolas conseguirão oferecer aos estudantes todos os itinerários formativos no Ensino Médio; esta situação se complexifica em pequenas cidades em que os estudantes não terão outra opção senão cursar aqueles itinerários ofertados por, não raro, uma única escola; um retrocesso que se materializa na redução de carga horária em todas as disciplinas de Ciências da Natureza (Física, Química e Biologia), desenhando uma perspectiva de uma formação básica sem aprofundamento de conceitos e conteúdos científicos necessários à construção do pensamento científico e à capacidade de argumentação a partir das ciências.

Para Moreira (2005), em tempos de mudanças rápidas e drásticas como os que vivemos, a aprendizagem deve ser crítica, subversiva, deve se opor à noção fora de foco de que quanto mais informação melhor, de idolatria à tecnologia, de uma percepção da educação como mercadoria. Para o autor, a aprendizagem crítica é aquela perspectiva que permite ao sujeito fazer parte de sua cultura e, ao mesmo tempo, estar fora dela, isto é, permite ao estudante participar das atividades sociais e científicas, da cultura, da sociedade, mas, ao mesmo tempo, reconhecer quando a realidade está se afastando tanto que não está mais sendo captada pelo grupo (e.g., quando negacionismos e movimentos anti ciência passam a ser assumidos, muito em função do desconhecimento de uma parte significativa da população acerca do que é a ciência). É neste sentido que defendemos que a formação do pensamento científico é crucial para que, efetivamente, o sujeito possa participar e transformar a sociedade na qual está inserido. Daí a nossa defesa para uma não redução de carga horária das Ciências da Natureza.

Não podemos deixar de reconhecer, com relação ao Ensino Fundamental, que uma maior quantidade de temas de ciências, especialmente mais Física e Astronomia, está prevista na BNCC, de forma diluída desde os Anos Iniciais. Contudo, entendemos que o lugar de aprofundar esse conhecimento, que é inicialmente abrangente e geral, é no Ensino Médio, com o objetivo de favorecer a compreensão de conceitos mais complexos (vários destes estão previstos no Referencial Curricular Gaúcho e alguns foram citados neste texto).

O Referencial Curricular Gaúcho também não prezou pela regionalidade, não buscando alinhar as habilidades presentes na BNCC com os problemas locais. Isso poderia ter sido realizado em pelo menos duas instâncias, por exemplo: ao considerar as especificidades da indústria gaúcha, como no caso da matriz energética predominante no estado na habilidade EM13CNT107; e ao considerar a cultura local, como a contribuição africana e indígena na Astronomia das Culturas.

Outra reflexão preocupante com respeito à inflexão dos documentos oficiais brasileiros a partir de 2016, com reflexos também no documento gaúcho, diz respeito à mudança na forma como devemos 
interpretar a Educação, como o direito à aprendizagem o que, embora seja um direito, reduz o conceito de Educação enquanto direito social fundamental. Além disso, não especificam os sujeitos de direitos, privados historicamente, desvalorizam a diversidade cultural e deixam de promover a equidade étnico-racial, como mostrado na seção precedente.

O retrocesso antes mencionado também se estende à formação de professores para o Ensino Básico, pois a maioria das Licenciaturas do país foram reestruturadas com base nas Diretrizes Curriculares de Formação de Professores de 2015 (BRASIL, 2015a; 2015b) e ainda não houve tempo suficiente para uma avaliação adequada pelas IES, momento em que tal normativo foi revogado e em seu lugar surgem as Diretrizes Curriculares de 2019 (BRASIL, 2019) que sinalizam que a qualificação docente deixa de ser uma função do Estado e passa a ser um investimento pessoal dos profissionais da educação, que tornam o engajamento e a formação cívica e transformadora num aperfeiçoamento técnico (que tem no horizonte uma concepção de sujeito resumido às relações do mercado de trabalho), que substitui a gestão democrática do ensino por uma concepção baseada em governança e indicadores técnicos e que reduz a aprendizagem específica aprofundada e articulada a dimensões pedagógicas e contendo, no caso dos cursos de Licenciatura em Física da UFRGS, práticas como componente curricular desde o primeiro semestre (e.g., MASSONI, BRUCKMANN, ALVES-BRITO, 2020) à mera aprendizagem dos objetos de conhecimento previstos na BNCC da Educação Básica; BNCC esta que, como mencionado, a exemplo da Common Core (apoiada pela Fundação Gate, nos Estados Unidos), no Brasil, foi suportada técnica e financeiramente pela Fundação Lemann (TARLAU; MOELLER, 2020), que buscou garantir a produção de uma BNCC à imagem e semelhança da Lemann, com a aplicação de princípios de investimento privado à educação (gestão pautada em avaliações, avaliação docente por meritocracia, aulas roteirizadas etc.) e que abre possibilidades para a entrada na gestão da Educação de novos agentes, especialmente da iniciativa privada, cujos resultados podem ser desfavoráveis aos mais pobres, aos historicamente excluídos de uma educação pública de qualidade Alinhamo-nos a Rodrigues, Pereira e Mohr (2020) no sentido de que o momento demanda muita atenção e análise não só das propostas e consequências destas novas políticas, mas também dos fundamentos que o embasam e dão razão para sua existência.

\section{REFERÊNCIAS}

ABdC. Documento produzido pela Associação Brasileira de Currículo (ABdC) encaminhado ao CNE no contexto das Audiências públicas sobre a BNCC /2017. Site da Associação Brasileira de Currículo (ABdC), 2017. Disponível em: https://1fce3adf-21b8-44d9-9b12da4e0971a909.filesusr.com/ugd/f7609a_c4732add5942400faee446d99c3e1158.pdf. Acesso em 30 de mar. de 2021.

ALVES-BRITO, A., BOOTZ, V.; MASSONI, N. T. Uma sequência didática para discutir as relações étnico-raciais (Leis 10.639/03 e 11.645/08) na educação científica. Caderno Brasileiro de Ensino de Física. Florianópolis, v. 35, p. 917-955, 2018.

AUSUBEL, D. Aquisição e Retenção de Conhecimentos: Uma Perspectiva Cognitiva. Lisboa: Paralelo Editora, 2003.

AYENE, M.; KRICK, J.; DAMITIE, B.; INGERMAN, A.; THACKER, B. A Holistic Picture of Physics Student Conceptions of Energy Quantization, the Photon Concept, and Light Quanta Interference.

Int Journal of Sci and Math Educ, v. 17, p.1049-1070, 2018. 
BRASIL. Constituição Federal de 1988. Disponível em:

http://www.planalto.gov.br/ccivil_03/constituicao/constituicao.htm. Acesso em 05 de abril de 2021.

BRASIL. Lei Federal no 9.394 de 20 de dezembro de 1996: Estabelece as diretrizes e bases da educação nacional. Brasília, 1996. Disponível em:

http://www.planalto.gov.br/ccivil_03/leis/19394.htm. Acesso em 30 de mar de 2021.

BRASIL, Parâmetros Curriculares Brasileiro (Ensino Médio): bases legais. Brasília: Ministério da Educação, 2000. Disponível em: http://portal.mec.gov.br/seb/arquivos/pdf/blegais.pdf. Acesso em 30 de mar de 2021.

BRASIL. Lei 10.098, de 19 de dezembro de 2000. Disponível em:

https://www.planalto.gov.br/ccivil_03/leis/l10098.htm. Acesso em 04 de abril de 2021.

BRASIL. Lei 10.639, de 09 de janeiro de 2003. Disponível em:

http://www.planalto.gov.br/ccivil_03/leis/2003/L10.639.htm. Acesso em 05 de abril de 2021.

BRASIL. Lei 11.645, de 10 de março de 2008. Disponível em:

http://www.planalto.gov.br/ccivil_03/_ato2007-2010/2008/lei/l11645.htm. Acesso de 05 de março de 2021.

BRASIL. Lei 13.005 de 25 de junho de 2014: Aprova o Plano Nacional de Educação. Brasília, 2014. Disponível em: http://www.planalto.gov.br/ccivil_03/_ato2011-2014/2014/lei/l13005.htm. Acesso em 30 de mar de 2021.

BRASIL. Lei 13.146 de 06 de julho de 2015. Disponível em: https://www.planalto.gov.br/ccivil_03/_ato2015-2018/2015/lei//13146.htm.

BRASIL. Conselho Nacional de Educação/Conselho Pleno. Diretrizes Curriculares Nacionais para a Formação Inicial e Continuada dos Profissionais do Magistério da Educação Básica. Parecer CNE/CP 2/2015. Brasília: Diário Oficial da União, Seção 1, p. 13, 25 jun. 2015. (2015a).

BRASIL. Conselho Nacional de Educação. Diretrizes Curriculares Nacionais para a formação inicial em nível superior (cursos de licenciatura, cursos de formação pedagógica para graduados e cursos de segunda licenciatura) e para a formação continuada. Resolução CNE/CP n. 02/2015, de $1^{\circ}$ de julho de 2015. Brasília: Diário Oficial da União, Seção 1, n. 124, p. 812, 02 jul. 2015. (2015b)

BRASIL. Lei 13.415 de 2017: Altera as Leis no 9.394, de 20 de dezembro de 1996 (...). Brasília, 2017. Disponível em: http://www.planalto.gov.br/ccivil_03/_Ato2015-2018/2017/Lei/L13415.htm. Acesso em 30 de mar de 2021.

BRASIL. Base Nacional Comum Curricular. Brasília: Ministério da Educação, 2018. Disponível em: http://basenacionalcomum.mec.gov.br/images/BNCC_EI_EF_110518_versaofinal_site.pdf. Acesso em 30 de mar de 2021.

BRASIL. Ministério da Educação. Resolução no 3, de 20 de novembro de 2018. Estabelece as Diretrizes Curriculares Nacionais para o Ensino Médio. Diário Oficial da União, Brasília, 22 de novembro de 2018

BRASIL. Resolução no CNE/CP n. 2, de 20 de dezembro de 2019. Brasília, 2019. Disponível em: http://portal.mec.gov.br/docman/dezembro-2019-pdf/135951-rcp002-19/file. Acesso 04 de abril de 2021. 
BRUNER, J. The Process of Education. Cambridge, Massachusetts: Harvard University Press, 1960.

CLAVIJO M. R.; WALTEROS, A.; CORTÉS, C. La actividad experimental como una parte fundamental para la enseñanza de la física moderna: el caso de la mecánica cuántica. Tecné Episteme y Didaxis: TED, Colômbia, n. 45, p. 191-206, 2019.

HERAUD, J; LAUTESSE, P.; FERLIN, F.; CHABOT, H. Representing the Quantum Object Through Fiction in Teaching. The Ontological Contribution of Gamow's Narrative as Part of an Introduction to Quantum Physics. Sci \& Educ, v. 26, p. 299-322, 2017.

FINLAY, G. C. Secondary school physics: The Physical Science Study Commitee. American Journal of Physics, v. 28, p. 574-581, 1960.

FREITAS, F. M.; SILVA, J.; LEITE, M. C. L. Diretrizes invisíveis e regras distributivas nas políticas curriculares da nova BNCC. Currículo sem Fronteiras, v.18, n.3, p.857-870, set./dez. 2018. Disponível em: https://www.curriculosemfronteiras.org/vol18iss3articles/freitas-silva-leite.pdf. Acesso em 30 de mar. de 2021.

MARKIN, A. V.; MARKINA, N. E.; EILKS I. The application of laser pointers for demonstration experiments in nanotechnology lessons at secondary school level. Proc. of SPIE, v.10336, p. 103360S/1-103360S/8, 2017.

MASSONI, N. T.; BRUCKMANN, M. E.; ALVES-BRITO, A. Reestruturação Curricular do curso de Licenciatura em Física da UFRGS: o processo de repensar a formação docente. Revista Educar Mais, vol. 4, n. 3, p. 512-541, 2020.

MEC. O conteúdo da BNCC foi construído democraticamente? Site da BNCC, s/d. Disponível em: http://basenacionalcomum.mec.gov.br/a-base. Acesso em: 30 de mar. de 2021.

MOREIRA, M. A. Aprendizagem Significativa Crítica. 2005. Disponível em: http://moreira.if.ufrgs.br/apsigcritport.pdf. Acesso em 05 de abril de 2021.

MUNERATTO, Felipe. et al. A constituição do grupo de elaboração da BNCC de Ensino de Ciências: trajetórias de seus atores sociais e seus impactos na elaboração da proposta. Dourados-MS:

Horizontes - Revista de Educação, v. 8, n. 15, p. 113-132, 2020. Disponível em: https://ojs.ufgd.edu.br/index.php/horizontes/article/view/12283. Acesso 30 de mar. de 2021.

NASCIMENTO, M. M. O professor de Física na escola pública estadual brasileira: desigualdades reveladas pelo Censo escolar de 2018. Revista Brasileira de Ensino de Física, São Paulo, v. 42, e20200187, 2020. Doi: 10.1590/1806-9126-rbef-2020-0187.

NOGUEIRA, M. A.; NOGUEIRA, C. M. M. Bourdieu \& a Educação. 4a ed. Belo Horizonte: Autêntica Editora, 2017.

REIS, P. Desafios à Educação em Ciências em Tempos Conturbados. Ciência \& Educação, v. 27, e21000, 2021. Doi:10.1590/1516-731320210000.

RODRIGUES, L. Z.; PEREIRA, B.; MOHR, A. O Documento "Proposta para Base Nacional Comum da Formação de Professores da Educação Básica" (BNCFP): Dez Razões para Temer e Contestar a BNCFP. Revista Brasileira de Pesquisa em Educação em Ciências, vol, 20, p. 1-39, 2020. Doi: 10.28976/1984-2686rbpec2020u139.

ROSA, K.; ALVES-BRITO, A.; KARINE, B. Pós-verdade para quem? Fatos produzidos por uma ciência racista. Caderno Brasileiro de Ensino de Física, v. 37, n. 3 , p. 1440 -1468, 2020. 
SEDUC-RS. Consulta Pública - Referencial Curricular Gaúcho Novo Ensino Médio. site do Referencial Gaúcho. Disponível em: http://curriculo.educacao.rs.gov.br/BaseCurricular. Acesso em 30 de mar. de 2021.

STEVENS, S. Y.; DELGADO, C.; KRAJCIK, J. S. Developing a Hypothetical Multi-Dimensional Learning Progression for the Nature of Matter. Journal of Research in Science Teaching, v. 47, n. 6, p. 687-715, 2010.

TARLAU, R.; MOLLER, K. O Consenso por Filantropia: como uma fundação privada estabeleceu a BNCC no Brasil. Currículo sem Fronteiras, v.20, n.2, p.553-603, maio/ago. 2020. Disponível em: https://www.curriculosemfronteiras.org/vol20iss2articles/tarlau-moeller.pdf. Acesso em 30 de mar de 2021.

Submissão: 01/05/2021

Aceito: 05/05/2021 